\title{
Failure Analysis of Thin-Walled Composite Profile Subjected to Axial Compression
}

\author{
Patryk Różyło' \\ 1 Department of Machine Design and Mechatronics, Faculty of Mechanical Engineering, Lublin University of \\ Technology, ul. Nadbystrzycka 36, 20-618 Lublin, Poland \\ e-mail: p.rozylo@pollub.pl
}

\begin{abstract}
The paper describes a numerical and experimental study investigating the load carrying capacity of thin-walled composite structure subjected to axial compression. Composite profile was made of carbon-epoxy laminate with symmetrical arrangement of the layers [90/-45/45/0]s. The experiment was performed on a universal testing machine (Zwick Z100) until total failure of the column. In case of experimental study, post-critical equilibrium paths in full range of loads of the structure were determined. The numerical analysis was performed by the finite element method using the Abaqus ${ }^{\circledR}$ software. Numerical analysis involved solving a nonlinear stability problem. The geometrically non-linear problem was solved by the Newton-Raphson method. The load carrying capacity of the composite structure was determined by the progressive failure analysis, which firstly estimates damage initiation load (Hashin criterion) and secondly estimates failure load (energy criterion). The numerical and experimental results show high agreement, which confirms the adequacy of the prepared numerical model of composite profile.
\end{abstract}

Keywords: progressive failure analysis, finite element method, composite profile.

\section{INTRODUCTION}

Composite materials are one of the most outstanding engineering materials. Traditional isotropic materials, such as steel or aluminium are ever more frequently replaced by composite materials. Thin-walled composite structures have a high level of load capacity and rigidity, while their own mass remains very low. For this reason, composite materials prove more beneficial than the traditionally used ones. Since the materials used in aviation industry (but also construction, automotive or water industry) have to meet strict requirements, it is necessary to employ modern solutions based on thin-walled composite structures [1]. Due to the possibility of designing their features according to the current demand, composite materials can be widely used in the industry. Should there be a demand for a more significant energy consumption or structure rigidity, such features can be obtained by manipulating the laminate layer design, which significantly influences the properties of composite materials. Their orthotropic properties as well as the possibility of manipulating their features make composite materials suitable for extraordinary tasks [2].

Thin-walled composite structures often work not only in the range of the acceptable service load [3-6]. Since the aviation industry is a leader in the usage of composite materials (CFRP, GFRP), it dictates the conditions of safe structure work even if the acceptable service load is momentarily exceeded [7, 8]. For this reason, thin-walled composite structures are typically designed in such a way that would allow for working in a range that insignificantly exceeds the acceptable service load. The typical, generally used aviation structures, especially profiles with a channel- or omega-type cross-section in the hull of a fuselage in certain aircrafts are especially significant for the proper functioning, load capacity and the level of safety in service $[3,7-9]$. Due to the fact that the above mentioned structures carry significant loads it is necessary 
to conduct numerical analyses and experimental tests for this type of materials.

Thin-walled composite structures are characterized by the occurrence of critical state, wherein stability loss takes place [7]. Within the aforementioned structures a rapid change of the type of deformation can be observed (which is connected to the occurrence of geometrical nonlinearities) after reaching the load commonly known as critical load. It is possible for a thin-walled composite structure to work after stability loss, in the postcritical state, until damage [10]. Depending on the design of the laminate layers, a composite structure may, as a result of axial compression, carry an iteration of the critical load. This phenomenon is caused by the fact that constructions with certain layer design are damaged significantly later than others. The typical layer design occurring in composite structures is usually based on the angles $0^{\circ}$, $\pm 45^{\circ}$ and $90^{\circ}$. This subject-matter has been discussed in numerous scientific works [7-11].

The damage of composite structure, constituting the main subject of this study, is an extremely important issue. The phenomenon of damage is very complex and therefore requires an in-depth analysis. Within this study, the structure damage was conducted based on the following methods: in the case of experimental testing: deformation measurements and signals from the acoustic emission method, in the case of numerical calculations using the progressive failure analysis [10, $12,13]$. Due to the axial load applied to the structure, the issue of the initiation and evolution of the damage of the composite material was discussed [10-19]. In this case, the applied damage model describes the damage initiation in selected components of the composite material (damage to the fibres and matrix as a result of compression and tension) based on the Hashin criterion [20, 21]. Upon meeting the initiation criterion the damage evolution consists of a gradual degradation of the material properties and is described based on the energy criterion [22-26]. The methods applied in the research and the damage model in the case of numerical analysis allowed to assess the state of stability loss of a structure, which constituted the objective of the research.

\section{THE SUBJECT OF STUDY}

The subject of the research was a thin-walled composite column made of carbon-epoxy composite. The tested sample was manufactured using the autoclave technique. The sample consisted of 8 layers with a various arrangement in relation to the central surface of the laminate. The thickness of a single laminate layer was equal c.a. $0.131 \mathrm{~mm}$. The laminate layer configuration in the tested sample was $[0 /-45 / 45 / 90]_{\mathrm{s}}$. The actual sample and the shell computer model are presented in Figure 1.

The material properties for the actual sample were determined based on the standard compression and strength tests for composite materials. The mechanical and strength properties were estimated based on numerous experimental tests, e.g. using the universal testing machine Zwick Z100. The testing of material properties was conducted in room temperature using special heads a)

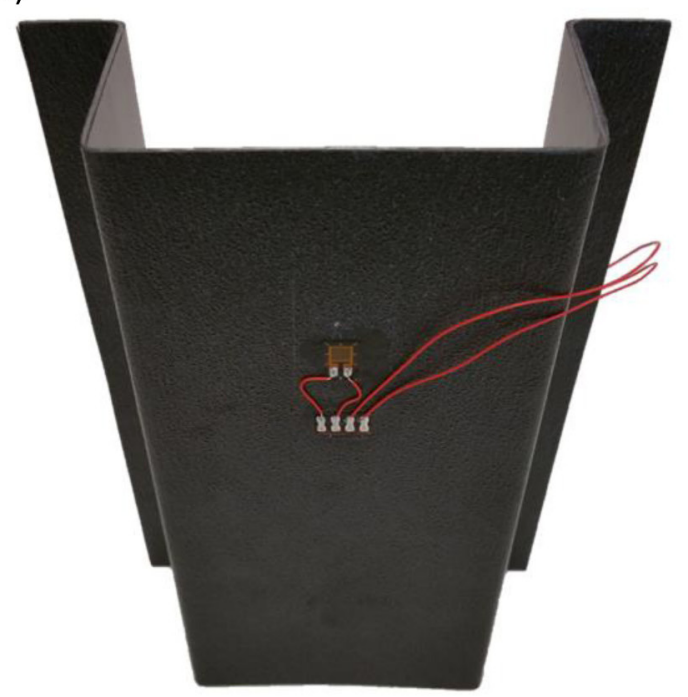

b)

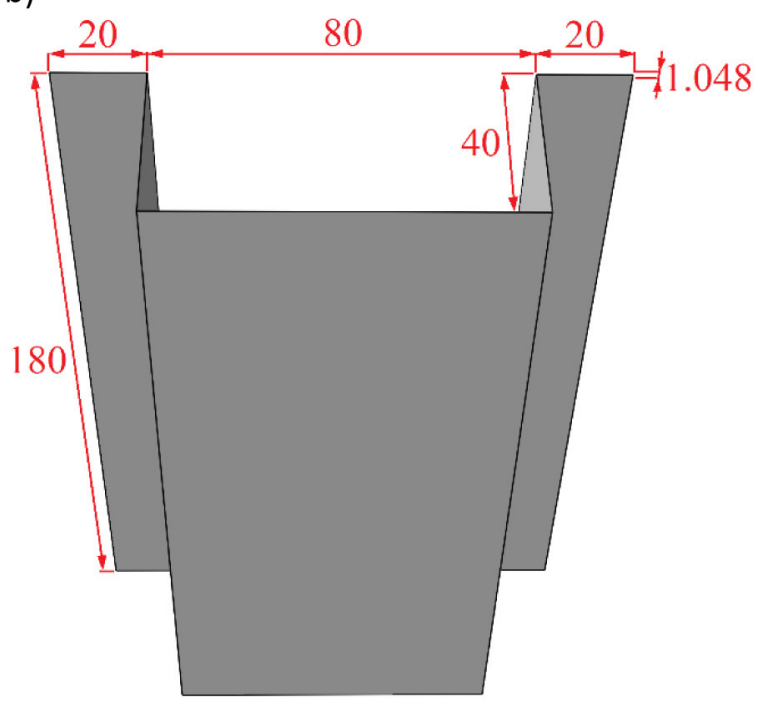

Fig. 1. Specimen: a) actual profile, b) shell computer model 
and paddle-shaped samples. The results of experimental testing are presented in Table $1[7,10]$.

\section{THE METHODOLOGY OF STUDY}

The damage of a composite structure was analysed as a part of the conducted research. Experimental testing of the process of axial compression of a structure was conducted in room temperature with the traverse moving at a constant speed equal $2 \mathrm{~mm} / \mathrm{s}$. The tests were ran using special heads with flat working surfaces, using additional panel bases, which ensured simple support to the end cross-sections of the column. The experimental tests were conducted for the full range of load, until the damage of the composite material. The boundary conditions for the real structure are presented further in the study in Figure 2a.

In the case of the experimental testing the analysis was organized in two stages (similarly to the numerical calculations). Firstly, the analysis of the critical state was performed, which allowed one to determine the critical load values (at which the structure changes the state of deformation - geometric nonlinearity occurs at significant deflections) [27]. The first stage of the research required the deflections caused by increased compressive strength to be measured. In order to achieve this, strain gauges were located on the opposite sides of the web of the composite profile - in the areas of the most significant deflections (which was estimated based on the results of initial numerical analyses). The strain gauges were located on the opposing sides of the web of the composite profile at the same height, in order to correctly measure the deflections. In the next stage the known methods of approximation of the curves force-deflection were employed, mainly the $\mathrm{P}-\mathrm{w}_{\mathrm{c}}{ }^{2}$ and Koiter method [28].

In the case of the $\mathrm{P}-\mathrm{w}_{\mathrm{c}}{ }^{2}$ method the estimation of the critical force is based on the load-square of a difference of the deflections. In the case of the described method, the results of approximation are compliant with the linear function expressed by the following equation (1) [28]:

$$
P=P_{c r} \frac{a_{1}}{a_{0}} w+P_{c r}
$$

where: $a_{0}, a_{1}$ - unknown parameters,

$P$ - applied load,

$P_{c r}$ - unknown critical load,

$w \sim\left(e_{1}-e_{2}\right)^{2}-$ increase in the deformation proportional to the increase in the deflection.

The Koiter method is closely linked to the post-critical equilibrium path, describing the relation load-difference of deformations measured on the opposite sides of the web of the profile. The results of the analysis of the weakly post-critical state are similar in description to the seconddegree quadratic function in the case of the Koiter method, with the following equation [28]:

$$
P=P_{c r} \frac{a_{2}}{a_{0}} w^{2}+P_{c r} \frac{a_{1}}{a_{0}} w+P_{c r}
$$

where: $a_{0}, a_{1}, a_{2}-$ unknown parameters of the function,

$P$ - applied load,

$P_{c r}$ - unknown critical load,

$w \sim\left(e_{1}-e_{2}\right)^{2}$ - increase in the deformation proportional to the increase in the deflection.

In the case of the both methods the critical load can be defined as an intersection of the approximation function with the vertical axis of the characteristics, which is the axis of the load. The comprehensive method of determining the critical load was presented in the study [7, 28]. Within the process of determining the critical load it is vital to properly select the approximating range of the initial curve in such a way that the correlation coefficient $R^{2} \geq 0.95$, ensuring the compliance of the approximating function with the approximated characteristic, was at the level of at least $95 \%[7,28]$.

Based on both of those approximating methods it was possible to determine the approximate values of the critical load, in the further part of the study compared to the results of the numerical calculations. In the second stage of the experimental

Table 1. Material properties of carbon-epoxy laminate in [MPa]

\begin{tabular}{|c|c|c|c|c|c|c|c|c|}
\hline \multicolumn{2}{|c|}{$\mathrm{F}_{\mathrm{TU}}$} & \multicolumn{2}{|c|}{$\mathrm{E}_{\mathrm{T}}$} & $\mathrm{v}_{12}$ & $\mathrm{~F}_{\mathrm{SU}}$ & $\mathrm{G}$ & \multicolumn{2}{c|}{$\mathrm{F}_{\mathrm{CU}}$} \\
\hline $0^{\circ}$ & $90^{\circ}$ & $\mathrm{E}_{1}\left(0^{\circ}\right)$ & $\mathrm{E}_{2}\left(90^{\circ}\right)$ & $0^{\circ}$ & $\pm 45^{\circ}$ & $\pm 45^{\circ}$ & $0^{\circ}$ & $90^{\circ}$ \\
\hline 1867 & 26 & 130710 & 6360 & 0.32 & 100 & 4180 & 1531 & 214 \\
\hline
\end{tabular}

The designations for the Table are as follows: $\mathrm{F}_{\mathrm{TU}}$ - tensile strength, $\mathrm{E}_{\mathrm{T}}-$ tensile modulus, $\mathrm{v}_{12}-$ Poisson ratio, $\mathrm{F}_{\mathrm{SU}}$ - shear strength, $\mathrm{G}$ - shear modulus, $\mathrm{F}_{\mathrm{CU}}$ - compressive strength. 
testing the analysis, until the damage of the material, was conducted. In order to achieve this the acoustic emission method was employed. A piezoelectric sensor, located directly on the shelf of the tested sample, allowed for recording the following parameters: number of counts, number of events, energy and the signal amplitude. Based on the conducted tests, the values of the load for both the damage initiation and the evolution (loss of construction stability) were determined.

In the case of the conducted numerical tests, the analysis consisted of two stages. In the first stage, the value of the critical load was determined, within a linear solution to an eigenproblem - based on the criterion of minimal potential energy of a system. Using the specific load and properly declared boundary conditions (Fig. 2b) allowed for determining not only the value of load at which the structure loses its stability, but also the type of buckling occurring. In the case of the calculations of the limit state the Hashin criterion was employed [20, 21]. This criterion considers four parameters of the damage of the composite material: (HSNFTCRT -damage to the material caused by the tension of the fibres, HSNFCCRT damage caused by the compression of the fibres, HSNMTCRT - damage caused by the tension of the MATRIX, HSNMCCRT -damage caused by the compression of the MATRIX). In the case of applying further load to the construction, until damage, the following five parameters are deciphered: DAMAGEFT - damage caused by the tension of the fibres, DAMAGEFC -damage caused by the compression of the fibres, DAMAGEMT - damage caused by the tension of the matrix, DAMAGEMC - damage caused by the compression of the matrix, DAMAGESHR damage caused by layer shear $[25,26]$. In the case of initiation for the respective compounds of the initiation or evolution criterion reaching the value equal 1 indicated the fulfilment of the criteria and therefore damage initiation or stability loss.

The numerical analysis was conducted using a model of a composite structure, consisting of deformable finite elements and models of plates, supporting the end cross-sections of the composite columns, made of non-deformable finite elements. In the case of the composite sample, the numerical model was prepared using surface finite elements with the second-order shape function with reduced integration - marked as $S 8 R$. In the case of plates, non-deformable surface elements were used, marked as R3D4. The obtained discrete model comprised of 11620 finite elements and 20187 nodes.

The boundary conditions for the numerical model adequately depicted the experimental testing. The discrete model of the composite column was supported by rigid plates, for which the boundary conditions were determined in reference points assigned for each plate. The nether plate was fully restrained/fixed in the reference point, whereas the upper plate moved in the direction of the compressive load. The condition of the compressive load was determined on the basis of the displacement of the upper plate in the direction of the $\mathrm{Z}$ axis, which allowed the simulation of the process of axial compression of the composite structure. Contact interactions were defined between the end cross-sections of the column and the non-deformable plates (contact in the tangential and normal direction, without considering the friction factor). Additionally, the nodes located on the edges of the cross-sections of the column were free to rotate in relation to the edges of the end cross-sections, but their dislocation in the directions perpendicular to the surface of the structure's walls was hindered.

Due to the fact that the numerical analysis was divided into two stages, in the process of calculating the critical state (eigenproblem), in the reference point of the upper plate the value of specific load, acting in compliance with the direction of the $\mathrm{Z}$ axis, was determined, instead of the dislocation causing compression of the structure. Such approach enabled one to determine the critical load. The second stage, considering the compression of the structure using a non-deformable plate was an analysis of the post-buckling stare (nonlinear stability problem) was conducted considering the initial imperfections, constituting 5\% of the thickness of the profile wall. Those imperfections match the first buckling state of the composite structure. The determined boundary conditions are presented in Fig. $2 b$ in a graphical form.

\section{RESULTS}

\section{Results of critical state}

The experimental tests and numerical simulations conducted allowed one to obtain the results for both the buckling and the boundary state (considering both the initiation and evolution of the damage to the composite material). The analysis of the buckling state was based on the obtained 
a)

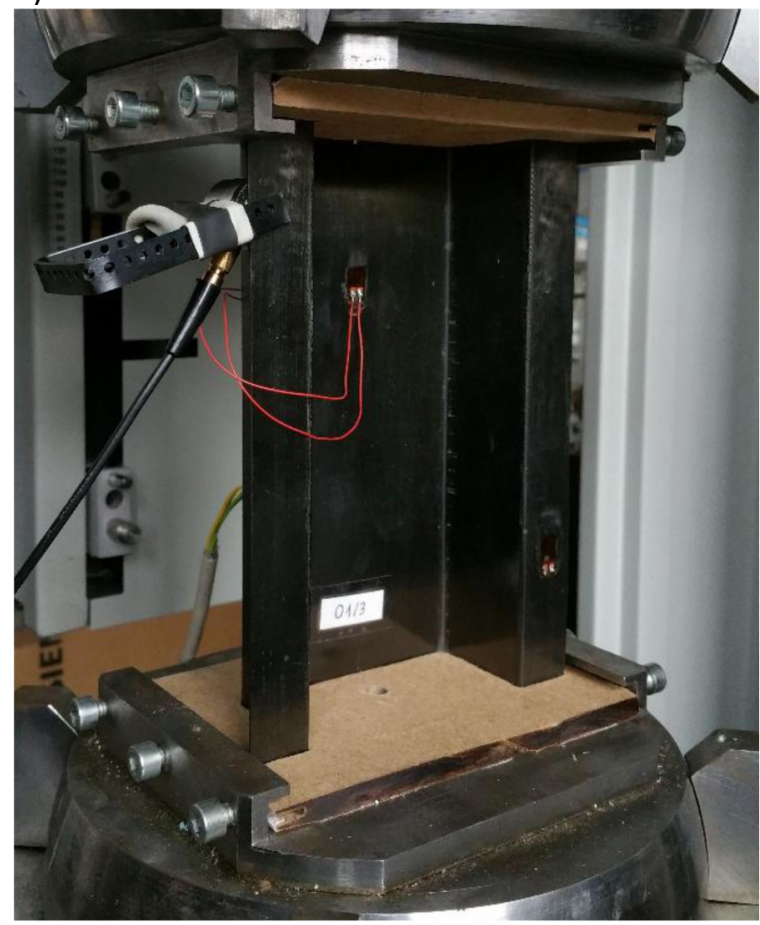

b)

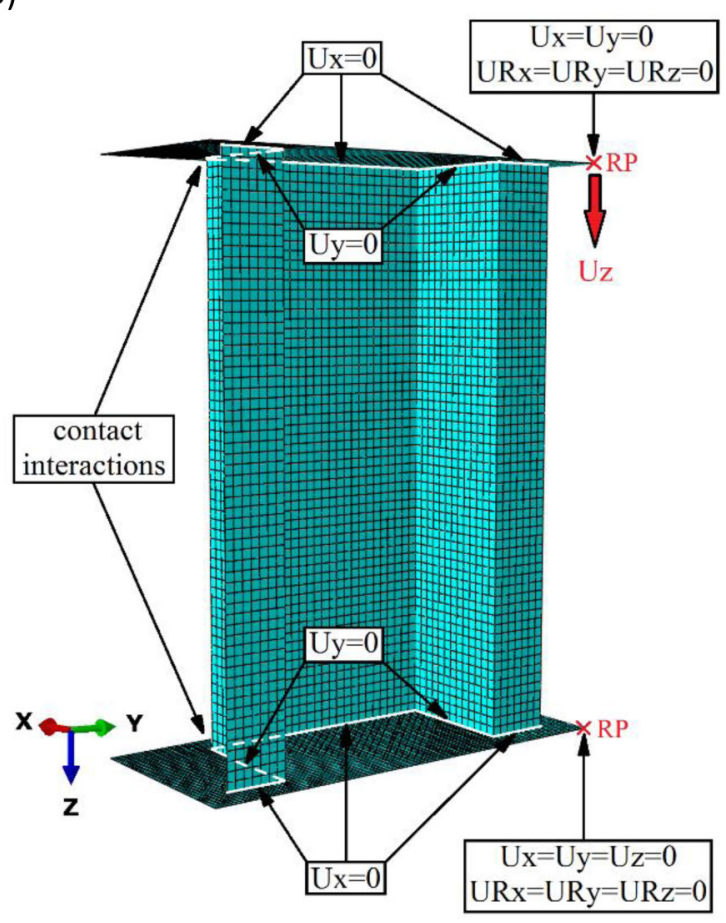

Fig. 2. Boundary conditions: a) actual structure, b) FEM model

values of critical load and the mode of construction buckling. In the case of experimental testing and numerical calculations the first mode of buckling was obtained in accordance to the criterion of the minimal energy necessary for the phenomenon to occur.

The aforementioned critical load values, in the case of experimental testing, were obtained based on the $\mathrm{P}-\mathrm{w}_{\mathrm{c}}^{2}$ and Koiter approximating methods, whereas in the case of FEM calculations the result was obtained by solving the linear eigenproblem. The obtained results of the critical state are presented in Figure 3.

In the obtained results a high agreement was observed in the case of the buckling state. In terms of the structure, a local buckling form, considering the occurrence of two half-waves. Those half-waves can be observed in the right vertical outer shelf of the composite profile, both in the experimental testing and numerical calculations. This phenomenon indicates that similar buckling modes were obtained within the research. In the case of numerical calculations the obtained value of the critical load, at which the structure buckled, was also presented. The value of the critical load in the case of the layer configuration employed in the research $[0 /-45 / 45 / 90]_{\mathrm{S}}$ is equal $\mathrm{P}_{\mathrm{cr}}$ $=6870.2 \mathrm{~N}$. With reference to the simultaneously conducted experimental testing the value of the critical load was determined based on two selected approximating methods - Fig. 4.

The research on the buckling state revealed a very significant quantitative compliance of the results, which is shown in Table. 2.

The obtained results of the experimental testing were compared to the values from numerical calculations. The discrepancy between the results of numerical calculations and the ones obtained by the Koiter method was equal c.a. $0.5 \%$, whereas in the case of the results of numerical calculations and $\mathrm{P}-\mathrm{w}_{\mathrm{c}}{ }^{2}$ method the discrepancy was $3.8 \%$. Both approximating methods allowed one to determine the values of the critical load with a high accuracy, compared to numerical analysis. The Koiter method allows for a significantly more accurate estimation of the values of the critical load, due to the use of the approximating function in the form of the second degree polynomial.

\section{Results of failure analysis}

The results connected to the occurrence of the damage phenomenon enabled one to assess the state of initiation and evolution of the damage to the composite material. The experimental testing of the limit state enabled one to assess the structure damage be comparing the results with the results of numerical calculations. It allowed 

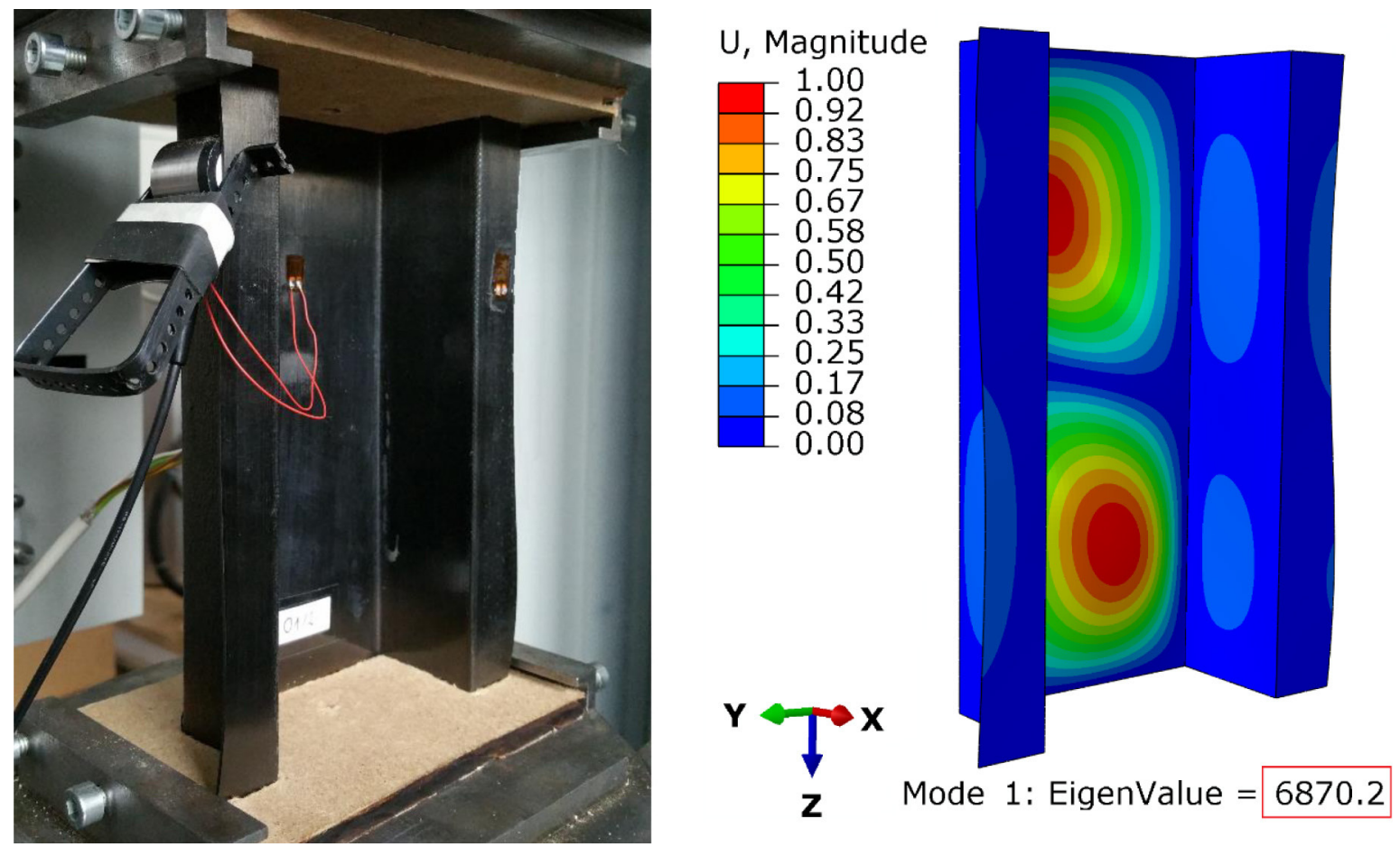

Fig. 3. Results of critical state: a) actual specimen, b) FEM model

a)

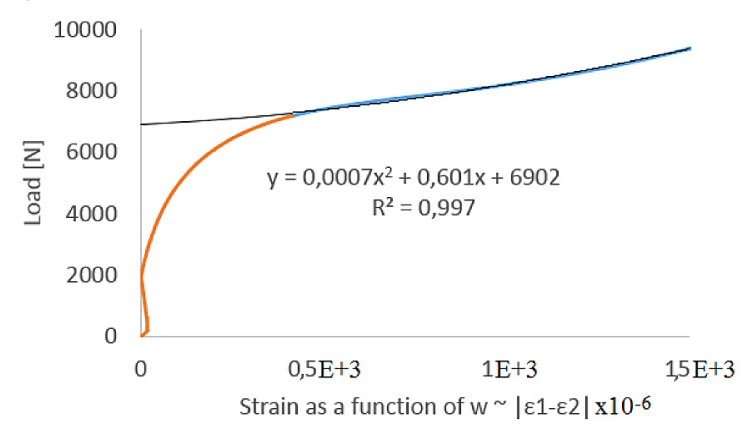

b)

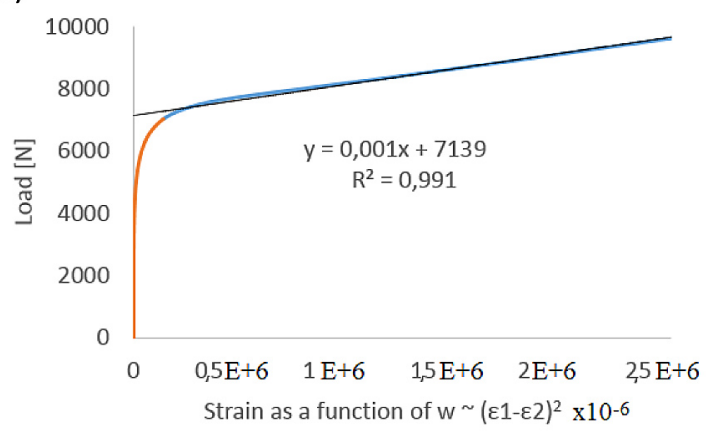

Fig. 4. Experimental approximation method: a) Koiter method, b) $\mathrm{P}-\mathrm{w}_{\mathrm{c}}{ }^{2}$ method

one to conduct a qualitative assessment of the phenomenon of damage to the structure made of composite material - Fig. 5.

On the basis of the research conducted it was observed that the initiation of the damage to the composite material occurred mainly in the nether and upper part of the inner, vertical edges of the structure (numerical calculations within the Hashin criterion) - Fig. 5b. The initiation and evolution criteria are met when the value of the damage parameter reaches 1 (the areas marked with red)

Table 2. Value of critical loads

\begin{tabular}{|c|c|c|c|}
\hline Trial & FEM & $\begin{array}{c}\text { Koiter } \\
\text { method }\end{array}$ & ${\mathrm{P}-\mathrm{w}_{\mathrm{c}}{ }^{2} \text { method }}$ \\
\hline $\begin{array}{c}\text { Critical load } \\
{[\mathrm{N}]}\end{array}$ & 6870.2 & 6902 & 7139 \\
\hline
\end{tabular}

or slightly exceeds it (areas marked in gray). In the case of the further testing of axial compression of the structure until its failure, the areas susceptible to stability loss were located. The stability loss, both in the case of experimental testing - Fig. 5b and numerical calculations, based on the progressive analysis of damage - Fig. 5c occurred in the nether part of the end cross-section of the composite column (the damage to the nether part of the profile in the nether part of the shelf is particularly visible). This type of damage occurs in short, thin-walled composite structures [10].

The damage initiation in the case of numerical calculations occurred as a result of meeting the damage component HSNMTCRT - damage caused by tension of the material matrix. Damage initiation constitutes only the process initiating the 


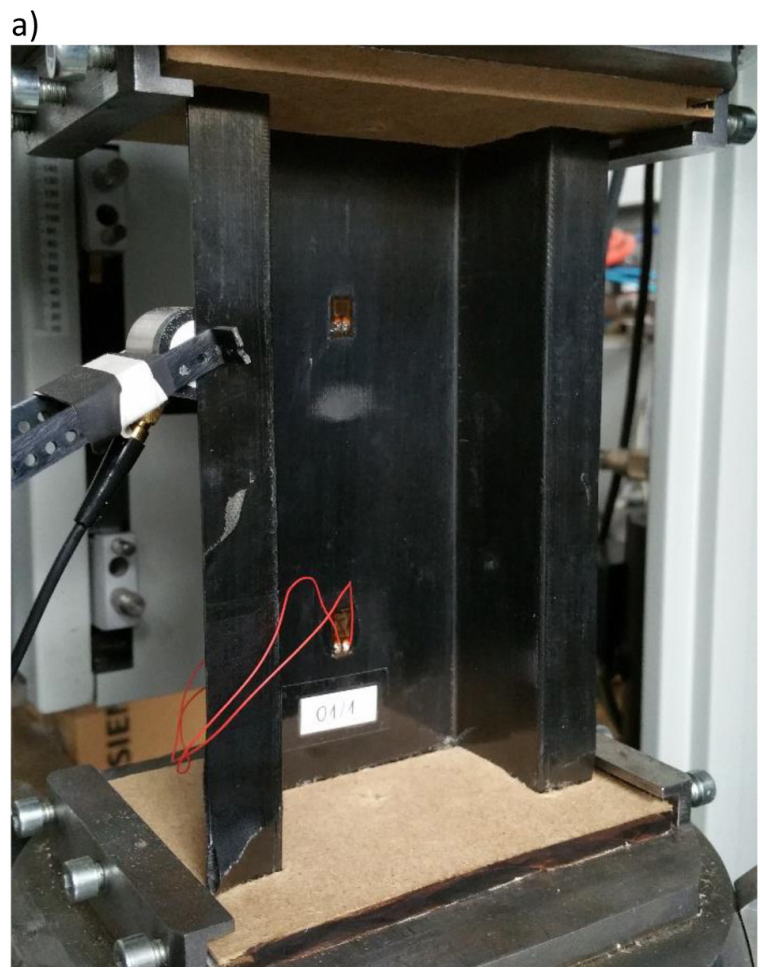

b)

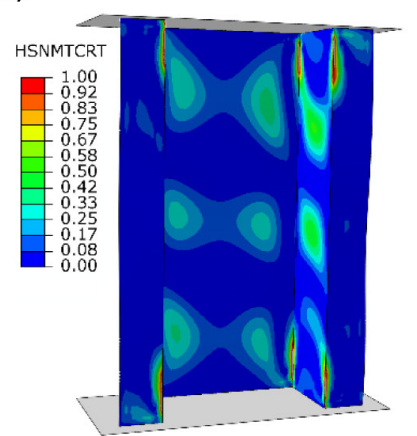

c)

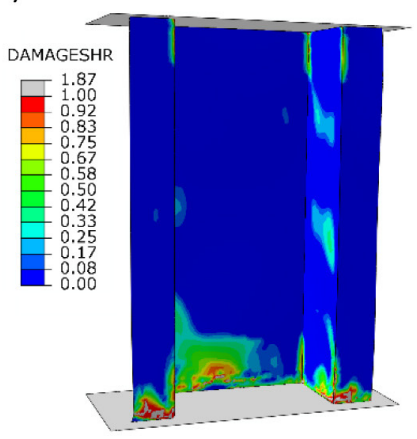

Fig. 5. Failure: a) experimental test, b) FEM - Hashin criterion, c) FEM - progressive failure analysis

damage to the composite material. However, only applying further load to the structure allows one to assess the stability loss of the structure (damage evolution). Damage evolution was initiated by the damage to the matrix caused by tension - DAMAGEMT, as it was in the case of damage initiation. The consecutively fulfilled evolution compounds were: damage caused by layer shear - DAMAGESHR, damage caused by fibre compression - DAMAGEFC and matrix damage caused by its compression - DAMAGEMC (the DAMAGEFT parameter, describing the damage caused by the tension of the fibres did not influence the stability loss). In the case of progressive damage analysis the damage evolution was presented based on one parameter of the damage evolution - DAMAGES$\mathrm{HR}$, damage to the material caused by layer shear.
In reference to the simultaneously conducted experimental testing and numerical calculations, the characteristics of the damage to the composite material were determined - Fig. 6 .

Within the research on the buckling state not only a very significant qualitative - Fig. 5, but also quantitative compliance was obtained. The results were presented in Table 3 .

Based on the examination of the buckling state, the values of the damage initiating load and the ultimate load (causing stability loss) were determined. In the case of numerical calculations it was observed that the load initiating the damage of the composite material is equal $9579 \mathrm{~N}$. Within the experimental testing the load was equal $10638 \mathrm{~N}$, which constitutes $9,95 \%$ discrepancy from FEM. In the case of the ultimate load, the

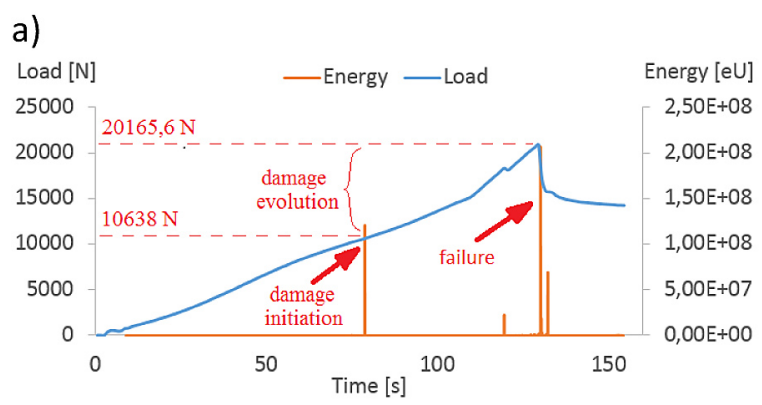

b)

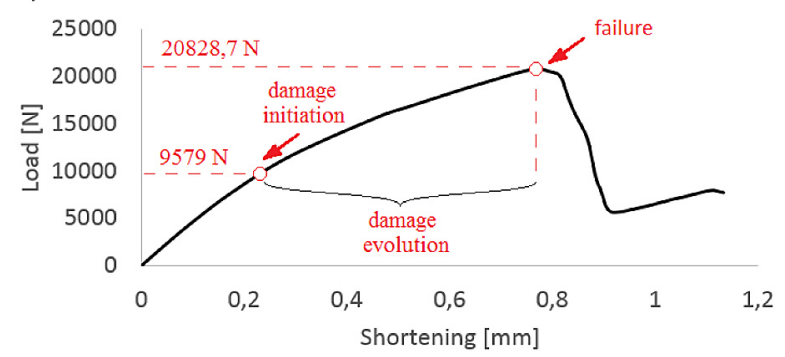

Fig. 6. Damage characteristics: a) experimental study - acoustic emission method,

b) FEM - progressive failure analysis 
Table 3. Value of damage initiation loads

\begin{tabular}{|c|c|c|c|}
\hline Trial & $\begin{array}{c}\text { Experimental } \\
\text { study [N] }\end{array}$ & FEM - PFA [N] & $\%$ \\
\hline $\begin{array}{c}\text { Damage } \\
\text { initiation load }\end{array}$ & 10638 & 9579 & 9,95 \\
\hline $\begin{array}{c}\text { Damage } \\
\text { evolution load }\end{array}$ & 20165,6 & 20828,7 & 3,18 \\
\hline
\end{tabular}

discrepancy value insignificantly exceeded 3\% (between the ultimate load value 20165,6 N experimental testing and 20828,7 N - numerical calculations). The ultimate load is over two times higher than the damage initiation load and over three times higher than the critical load.

\section{CONCLUSIONS}

The study presents the results of research on a composite column in the full range of load. The experimental testing of the physical model, manufactured using the autoclave method, enabled the validation of the numerical model, which allowed for describing the work of the structure (considering the phase of the damage to the composite structure). Employing the acoustic emission method in the experimental testing allowed one to assess the damage initiation in the real composite structure.

The numerical calculations conducted using the progressive composite damage criterion enabled one to conduct a description of the damage mechanisms in the composite material. The applied Hashin criterion allowed for identification of the composite damage initiation mechanism. This phenomenon was caused by the damage to the matrix as a result of tension. It also allowed for determining the value of the material damage initiation load. The progressive failure analysis used in the description of the damage evolution proved the fact that the damage of the structure of the composite material is complex. The results obtained from experimental testing and numerical calculations showed that the damage will occur in the nether part of the end cross-section of the column. In this case the numerically determined value of the ultimate load remained in compliance with the experimentally obtained value in over $96,5 \%$. For this reason the numerical model of the structure used for describing its work in the full range of load, including the description of the damage mechanisms of the composite material ought to be deemed adequate.

\section{Acknowledgments}

The research has been conducted under the project No. UMO-2015/19/B/ST8/02800 financed by the National Science Center Poland.

\section{REFERENCES}

1. Królak M., Stateczność. stany zakrytyczne i nośność cienkościennych konstrukcji o ortotropowych ścianach płaskich, Wyd. Politechniki Łódzkiej, seria Monografie, 1995.

2. German J., Podstawy mechaniki kompozytów włóknistych. Politechnika Krakowska, Kraków, 2001.

3. Rozylo P., Debski H., Kral J., Buckling and limit states of composite profiles with top-hat channel section subjected to axial compression, AIP Conference Proceedings 2018, 1922, 080001.

4. Debski H., Rozylo P., Gliszczynski A.: Effect of low-velocity impact damage location on the stability and post-critical state of composite columns under compression. Composite Structures 2018, 184, 883-893.

5. Ribeiro M.L., Vandepitte D., Tita V., Damage model and progressive failure analyses for filament wound composite laminates, Appl Compos Mater 2013, 20, 975-92.

6. Rozylo P., Optimization of I-section profile design by the finite element method, Advances in Science and Technology Research Journal, 2016, 10(29), 52-56.

7. Rozylo P., Teter A., Debski H., Wysmulski P., Falkowicz K., Experimental and numerical study of the buckling of composite profiles with open cross section under axial compression, Applied Composite Materials 2017, 24, 1251-1264.

8. Rozylo P., Experimental-numerical test of open section composite columns stability subjected to axial compression, Archives of Materials Science and Engineering 2017, 84(2), 58-64.

9. Rozylo P., Lukasik D.: Numerical analysis of the critical state of thin-walled structure with z-profile cross section. Advances in Science and Technology Research Journal 2017, 11(1),194-200.

10. Rozylo P., Debski H., Kubiak T.: A model of lowvelocity impact damage of composite plates subjected to Compression-After-Impact (CAI) testing. Composite Structures 2017, 181, 158-170.

11. Calzada K.A., Kapoor S.G., DeVor R.E., Samuel J., Srivastava A.K., Modeling and interpretation of fiber orientation-based failure mechanisms in machining of carbon fiber-reinforced polymer composites, Journal of Manufacturing Processes 2012, 14, 141-149.

12. Kubiak T., Samborski S., Teter A., Experimental 
investigation of failure process in compressed channel-section GFRP laminate columns assisted with the acoustic emission method, Composite Structures 2015, 133, 921-929.

13. Gliszczynski A., Kubiak T., Progressive failure analysis of thin-walled composite columns subjected to uniaxial compression, Composite Structures 2017, 169, 52-61.

14. Wang L., Zheng C., Luo H., Wei S., Wei Z., Continuum damage modelling and progressive failure analysis of carbon fiber/epoxy composite pressure vessel, Composite Structures 2015, 134, 475-482.

15. Liu P.F., Zheng J.Y., Progressive failure analysis of carbon fiber/epoxy composite laminates using continuum damage mechanics, Mater Sci Eng A 2008, 485, 711-717.

16. Tonatto M.L.P., Forte M.M.C., Tita V., Amico S.C., Progressive damage modelling of spiral and ring composite structures for offloading hoses, Mater Des 2016, 108, 374-82.

17. Lemaitre J., Plumtree A., Application of damage concepts to predict creep fatigue failures, J Eng Mater Technol 1979, 101(3), 284-92.

18. Iannucci L., Ankersen J., An energy based damage model for thin laminated composites, Compos Sci Technol 2006, 66, 934-51.

19. Li W., Cai H., Li Ch., Wang K., Fang L., Progressive failure of laminated composites with a hole under compressive loading based on micro-mechanics,
Adv Compos Mater 2014, 23(5-6), 477-90.

20. Hashin Z., Rotem A., A fatigue failure criterion for fibre reinforced materials, J Compos Mater 1973, 7, 448-64.

21. Hashin Z., Failure criteria for unidirectional fibre composites, J Appl Mech 1980, 47, 329-34.

22. Kachanov L.M., On the time to failure under creep conditions, Izv AN, Otd Tekhn 1958, 8, 26-31.

23. Camanho P.P., Maimí P., Dávila C.G., Prediction of size effects in notched laminates using continuum damage mechanics, Compos Sci Technol 2007, 67(13), 2715-27.

24. Camanho P.P., Matthews F.L., A progressive damage model for mechanically fastened joints in composite laminates, J Comp Mater 1999, 33, 2248-80.

25. Matzenmiller A., Lubliner J., Taylor LR., A constitutive model for anisotropic damage in fiber composites, Mech Mater 1995, 20, 125-52.

26. Lapczyk I., Hurtado J.A., Progressive damage modeling in fiber-reinforced materials, Composites Part A 2007, 38, 2333-2341.

27. Jones R.M., Buckling of bars, plates and shells. Bull Ridge Publishing, Blacksburg, Virginia, 2006, 308-319.

28. Paszkiewicz M., Kubiak T., Selected problems concerning determination of the buckling load of channel section beams and columns, Thin-Walled Structures 2015, 93, 112-121. 